\title{
The Harmonious Development of Big Data Industry and Financial Agglomeration in Guizhou
}

\author{
Lujing Pang, Mu Zhang \\ School of Big Data Application and Economics, Guizhou University of Finance and Economics \\ Guiyang Guizhou 550025, China \\ rim_007@163.com \\ 贵州大数据产业与金融集聚耦合协调发展研究 \\ 庞路静，张目 \\ 贵州财经大学大数据应用与经济学院, \\ 贵阳, 贵州, 550025, 中国 \\ rim_007@163.com
}

\begin{abstract}
In order to promote the coordinated development of big data industry and financial agglomeration, according to the characteristics of big data industry and financial agglomeration in Guizhou at this stage, the paper first understands the relevant literature of big data industry and financial agglomeration. Then, using the original data of nine cities in Guizhou from 2013 to 2017, we measure the development level of big data industry and financial agglomeration level of nine cities in Guizhou by using the hesitant fuzzy linguistic TOPSIS method and hesitant fuzzy linguistic PROMETHEE method respectively. Finally, the coupling coordination degree of big data industry and financial agglomeration in nine cities of Guizhou is calculated by using the coupling coordination model, and relevant policy recommendations are put forward. The empirical results show that Guiyang city is moderately coordinated development of big data industry and financial agglomeration, Zunyi city is reluctantly coordinated development, Liupanshui, Bijie and Southwest Guizhou are slightly maladjusted recessions, and the remaining cities are moderately maladjusted recessions. During the sample period, the degree of coupling and coordination between big data industry and financial agglomeration in Guizhou has been continuously improved, but the phenomenon of regional imbalance is more obvious.
\end{abstract}

Keywords-Big Data Industry; Financial Agglomeration; Coupling and Coordination; Hesitant Fuzzy Linguistic TOPSIS Method; Hesitant Fuzzy Linguistic PROMETHEE Method

摘要一为了促进大数据产业与金融集聚协调发展, 针对现 阶段贵州大数据产业和金融集聚的特点，文章首先了解了大 数据产业与金融集聚相关文献; 然后, 选取 2013-2017 年贵 州九个地州市的指标原始数据，分别运用犹豫模糊语言 TOPSIS 法和犹豫模糊语言 PROMETHEE 方法对贵州九个 地州市的大数据产业发展水平和金融集聚水平进行测度; 最 后运用耦合协调模型计算贵州九个地州市的大数据产业与金 融集聚的耦合协调度，并提出相关政策建议。实证结果表 明: 贵阳市为大数据产业与金融集聚中度协调发展, 遵义市 为勉强协调发展, 六盘水、毕节、黔西南是轻度失调衰退, 剩余州市为中度失调衰退。样本期间内, 总体上贵州大数据 产业与金融集聚耦合协调程度不断提高，但区域间不均衡现 象较为明显。

关键词一大数据产业, 金融集聚, 耦合协调, 犹豫模糊语 言 TOPSIS 法, 犹豫模糊语言 PROMETHEE 法

\section{I. 引言}

围绕实施国家大数据战略, 加强大数据在金融行业 领域的深入应用, 促进跨行业大数据融合创新, 推动大 数据与金融行业领域的融合发展, 对促进经济转型和创 新发展有重大意义。贵州正在建立大数据产业投融资体 系，鼓励金融机构为符合条件的大数据企业给予信贷支 持, 围绕大数据产业开发和创新金融产品, 延伸服务网 络, 为贵州大数据项目融资提供支撑 ${ }^{[1]}$ 。贵州建成全国 领先的大数据资源集聚地和大数据应用服务示范基地, 需要财政金融的大力支持和健全大数据产业投融资机 制, 大数据产业的发展也有利于金融行业改变传统的运 行方式和运行机制, 促进大数据金融服务业的发展。因 此, 对大数据产业与金融集聚协调发展现状进行分析, 有利于把握大数据产业与金融行业发展差异，促进行业 大数据应用发展。

目前而言，国内外学者大多集中于对金融集聚与产 业发展之间关系的研究。国外研究中, Rajan 和 Zingales (1998) ${ }^{[1]}$ 通过建立理论模型研究金融发展到一定程度 形成的金融集聚与产业结构之间的关系; Carlin 和 Mayer (2003) ${ }^{[2]}$ 从不同类型的金融结构角度出发, 研 究其对产业的影响; Audress 等 (2006) ${ }^{[3]}$ 阐述了金融集 聚带来的溢出效应显著提高了地区间的技术创新和产业 升级; Cotugno 等 (2013) ${ }^{[4]}$ 认为金融集聚下，产业结 构升级出现的空间溢出效用不但促进本地区的产业升 级, 同时也促进了周边地区产业的发展。国内研究中, 陈峰（1991） ${ }^{[5]}$ 最早研究了金融发展与产业发展之间的 关系; 孙晶和蒋伏心 (2013) ${ }^{[6]}$ 借助空间滞后模型和空间 误差模型进行研究发现, 金融集聚对区域产业结构升级 存在空间溢出效应; 杨义武和方大春 (2013) ${ }^{[7]}$ 运用面 板向量自回归模型研究金融集聚与产业结构变迁的互动 关系; 邓向荣和刘文强（2013） ${ }^{[8]}$ 实证分析了金融集聚 对产业结构升级作用; 郭露和丁峰（2015） ${ }^{[9]}$ 运用协调 发展度评价的改进模型对长三角地区 16 个地级市的三 大产业结构与金融集聚的分布进行综合评价与比较; 何 宜庆等 $(2015)^{[10]}$ 运用物理学中的三者耦合模型, 将金 融要素集聚、区域产业结构和生态效率三个系统相结 合，进行了耦合协调实证研究; 于斌斌 (2017) ${ }^{[11]}$ 认为 金融集聚对经济增长的影响是通过促进产业结构升级实 
现的; 谢婷婷和潘宇（2017） ${ }^{[12]}$ 构建产业结构和金融集 聚评价指标体系，应用耦合协调发展模型对产业结构和 金融集聚的耦合协调度进行了实证分析; 郭涁和张笑 （2018） ${ }^{[13]}$ 运用耦合协调模型分析金融集聚与产业结构 升级的耦合协调性。

从上述的国内外研究来看, 国外学者为国内学者立 足于我国实际情况对金融集聚和产业发展之间关系的研 究提供了理论支撑。但学者研究大多涉及的是金融集聚 与产业结构升级之间的关系，鲜有学者研究金融集聚与 具体的产业之间的关系。除此之外，由于我国大数据产 业起步较晚, 现有的文献仅对大数据产业的发展现状、 未来发展建议进行研究（迪莉娅, 2014 ${ }^{[14]}$; 李文娟, $2015^{[15]}$; 朝乐门，2016 $6^{[16]}$; 谢卫红等， $2018^{[17]}$ )，很少 涉及具体省份大数据产业发展水平、影响发展的因素， 大数据产业与金融集聚之间的发展研究更无系统性、完 善的理论体系。

在已有的学者研究基础上，本文首先对大数据产业 与金融集聚的耦合协调机理进行分析，然后选取 20132017 年贵州九个地州市的指标原始数据, 分别运用犹豫 模糊语言 TOPSIS 法和犹豫模糊语言 PROMETHEE 方法 对贵州九个地州市的大数据产业发展水平和金融集聚水 平进行测度，最后运用耦合协调模型计算贵州九个地州 市的大数据产业与金融集聚的耦合协调度，并提出相关 政策建议。

\section{II. 指标体系与数据来源}

\section{A. 指标体系建立}

结合贵州省大数据产业和金融行业发展的实际情 况, 本研究以科学性、系统性、全面性、可获得性为原 则, 把指标体系分为目标层、准则层和因素层。根据金 融集聚的内涵, 综合国内外相关研究成果, 参考中国

(深圳) 综合开发研究院发表的 “中国金融中心指数”

(China Financial Center Index，CFCI）编制原理从金融 业、银行业、保险业和证券业 4 个方面衡量贵州金融集 聚水平。根据大数据产业的内涵, 综合国内外相关研究 成果，参考工业和信息化部运行监测协调局发布的 “中 国电子信息产业综合发展指数” 编制原理，结合贵州地 级市大数据产业发展现状, 遵循科学性、代表性、客观 性、针对性、可比性及可操作性等评价指标选取原则, 以及大数据产业和金融集聚耦合协调发展的机制和特 征，构建大数据产业一金融集聚系统耦合协调发展评价 体系，各级指标和权重如表 1 所示。

表 1 大数据产业一金融集聚系统耦合协调发展评价体系 及权重

\begin{tabular}{clll}
\hline & $\begin{array}{c}\text { 一级指 } \\
\text { 标 }\end{array}$ & \multicolumn{1}{c}{ 二级指标 } & 权重 \\
\hline 金 & 金融业 & 金融业生产总值（亿 & 0.09 \\
融 & & 元） & \\
集 & & 金融业区位熵 & 0.04 \\
聚 & & 金融百度指数 & 0.06 \\
& & 年末金融机构存款余额 & 0.08 \\
& & (亿元) & \\
& & 银行业金融机构贷款余额 & 0.10 \\
& & (亿元) & \\
& & &
\end{tabular}

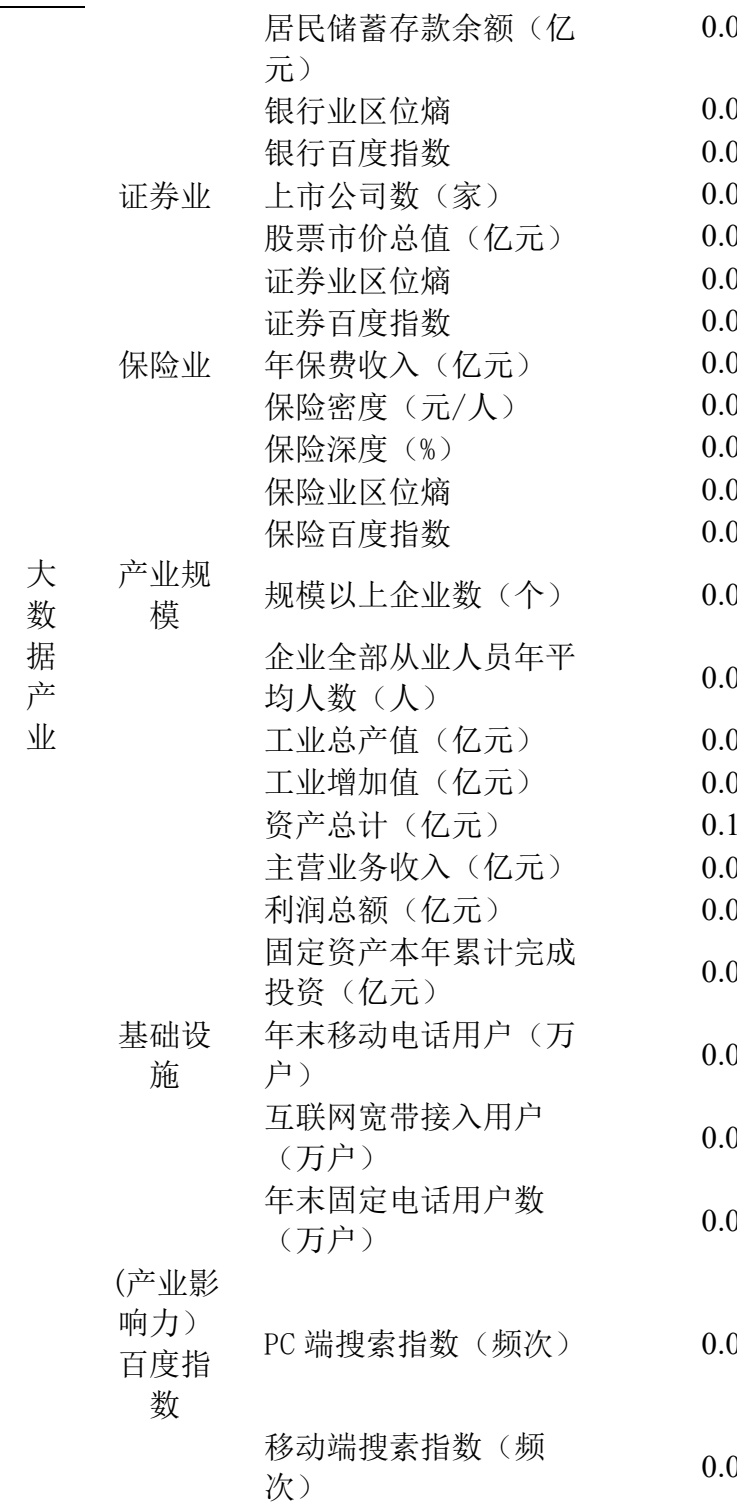

0.05

0.01

0.06

0.09

0.09

0.06

0.08

0.06

0.04

0.02

0.02

0.05

0.07

0.07

0.09

0.09

0.10

0.09

0.06

0.08

0.05

0.06

0.08

注: 为保持客观性, 本章实证研究采用熵权法计算大数据产业一金融集聚 系统耦合协调发展评价体系指标权重。由贵州省数据可得 2013 至 2017 年 各指标属性权重, 为统一权重值, 将每个属性各年份的权重求算术平均 值, 得表 1 中最终指标权重值。

指标说明: 1) 指标体系中的区位熵, 又称专门化 率。其作为衡量某一区域要素的空间分布情况的指标, 反映了某一产业部门的专业化程度, 可具体比较各地区 产业集聚程度差异。2）百度搜索指数，是以网民在百 度的搜索量为数据基础, 以关键词为统计对象, 科学分 析并计算出各个关键词在百度网页搜索中搜索频次的加 权和。根据搜索来源的不同, 百度搜索指数分为 PC 搜 索指数和移动搜索指数 (http://index.baidu.com)

\section{B. 数据来源}

本章实证研究选取 2013 至 2017 年各综合评价体系 指标数据, 数据来源于贵州各地级市和自治州统计年 鉴、贵州省统计年鉴、中国银保监会、中国证监会、贵 州省统计局、贵州各地州市、统计局政府官网和百度指 数网站。金融集聚方面, 百度指数网站上分别输入 “金 融”、“银行”、“证券”、“保险” 四个关键词, 选 择 “ $\mathrm{PC}+$ 移动端” 搜索指数, 同时将选择地区分别定位 在贵州省九个地州市, 即获取贵州省九个地州市每年关 键词搜索频次的平均值。因为没有 “大数据产业” 这一 关键词的搜索指数, 所以我们使用百度指数中收录的关 
键词 “大数据” 进行 PC 端和移动端的分别搜索,得到的 百度指数作为大数据产业影响力指标数据, 以此形成本 文研究的数据基础。由于贵州省部分地级市金融业生产 总值的不可获得性，本文采取将年末金融机构存款余 额、股票市价总值和年保费收入加总后的值作为金融业 生产总值的替代值, 个别缺失的数据通过一系列的估算 方法得到。

\section{III. 实证方法}

\section{A. 基于犹豫模糊语言的 TOPSIS 综合评价方法}

设 $\mathrm{X}=\left\{x_{1}, x_{2}, \ldots, x_{n}\right\}$ 为方案集, $\mathrm{C}=\left\{c_{1}, c_{2}, \ldots, c_{m}\right\}$ 为属性集,

$\mathrm{W}=\left\{w_{1}, w_{2}, \ldots w_{m}\right\}$ 是属性的权重向量, 满足 $\mathrm{w}_{j} \in[0,1]$, 且 $\sum_{j}^{m} \mathrm{w}_{j}=1$, 权重通过熵权法计算得 出 语言标度 $\mathrm{S}=\left\{s_{\alpha} \mid \alpha=-\tau, \ldots,-1,0,1, \ldots, \tau\right\}$, 各专家在 此标度下给出方案 $x_{i}$ 在属性 $c_{j}$ 下的评估, 并通过 $E_{G_{H}}$ 转化 为犹豫模糊语言集。通过决策对方案进行排序, 对方案 进行比较。基于犹豫模糊语言的 TOPSIS 法计算步骤如 下:

步骤 1: 通过文本自由法将语言信息转化成犹豫模 糊语言集, 得到犹豫模糊语言决策矩阵 $\mathrm{R}=\left(H_{S}^{i j}\right)_{n \times m}$, 其中 $H_{S}^{i j}$ 表示专家对方案 $x_{i}$ 在属性 $c_{j}$ 下的语言评价值。因 此犹豫模糊语言决策矩阵可表示成如下:

$\mathrm{R}=\left(H_{S}^{i j}\right)_{n \times m}=\left\{\begin{array}{cccc}H_{S}^{11}\left(x_{1}\right) & H_{S}^{12}\left(x_{1}\right) & \ldots & H_{S}^{1 m}\left(x_{1}\right) \\ H_{S}^{21}\left(x_{2}\right) & H_{S}^{22}\left(x_{2}\right) & \ldots & H_{S}^{2 m}\left(x_{2}\right) \\ \vdots & \vdots & \ddots & \vdots \\ H_{S}^{n 1}\left(x_{n}\right) & H_{S}^{n 2}\left(x_{n}\right) & \ldots & H_{S}^{n m}\left(x_{n}\right)\end{array}\right\}$

(1) 对于不同的 $H_{S}^{i j}$, 可能包含的语言术语的 个数是不相同的, 我们选择添加某虚拟语言术语到较少 $H_{S}^{i j}$ 之中, 使得不同的 $H_{S}^{i j}$ 所包含的语言术语的个数是相 同的。设 $\mathrm{b}=\left\{b_{l} \mid l=1,2, \ldots, \# b\right\}$ 为犹豫模糊语言数, $\# b$ 为 $b$ 中语言术语的个数, 令 $b^{+}$和 $b^{-}$为 $b$ 中的最大和最 小语言术语, $\xi(0 \leq \xi \leq 1)$ 为最优参数, 则可添加语言

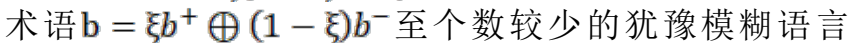
中。 $\xi$ 的取值取决于决策者对风险的态度。乐观的决策 者会选择添加最大的虚拟语言术语, 即 $\xi=1$ 。悲观的决 策者则选择增加最小的虚拟语言术语, 即 $\xi=0$ 。中立型 的决策者则会取 $\xi=\frac{1}{2}$ 。因为决策者对风险的态度不一致 最终决策结果也将不相同。本文中我们取 $\xi=\frac{1}{2}$ 。

例 如 : $H_{S}^{11}=\left\{s_{1}, s_{2}\right\}, H_{S}^{12}=\left\{s_{1}\right\}$ ， $H_{S}^{13}=\left\{s_{1}, s_{2}, s_{3}\right\}$, 则对于 $H_{S}^{11}$ 我们添加 $s_{1.5}=\frac{s_{1} \oplus s_{2}}{2}$ 到 $H_{S}^{11}$ 中, 即得到 $H_{S}^{11}=\left\{s_{1}, s_{1.5}, s_{2}\right\}$, 同理 $H_{S}^{12}=\left\{s_{1}, s_{1}, s_{1}\right\} 。$

步骤 2: 得到犹豫模糊语言的正负理想解。正理想 解 $A^{+}=\left\{H_{s}^{1+}, H_{s}^{2+}, \ldots, H_{s}^{n+}\right\}$, 负 理 想 解
$A^{-}=\left\{H_{s}^{1-}, H_{s}^{2-}, \ldots, H_{s}^{n-}\right\}$, 其中对于效益型的指标而言 正理想解是由每一列最大的一个犹豫模糊语言术语组 成, 负理想解是由每一列最小的一个犹豫模糊语言术语 组成。而对于成本型指标而言, 正理想解是由每一列最 小的一个犹豫模糊语言术语组成, 负理想解是由每一列 最大的一个犹豫模糊语言术语组成。

步骤 3: 计算方案 $x_{i}$ 与正、负理想解之间的加权距 离 $D_{i}^{+}$和 $D_{i}^{-}$。在计算加权距离之前我们先来了解一下两 个犹豫模糊语言集之间的欧式距离。设扩展标度 $\bar{S}=\left\{S_{i} \mid i \epsilon[-q, q]\right\} \quad, \quad H_{S}^{11}=\left\{b_{1}^{11}, b_{2}^{11}, \ldots, b_{l}^{11}\right\} \quad$ 和 $H_{S}^{22}=\left\{b_{1}^{22}, b_{2}^{22}, \ldots, b_{l}^{22}\right\}$, 记 $\delta($.$) 为虚拟语言术语的下$ 标。令

$\mathrm{d}\left(H_{S}^{11}, H_{S}^{22}\right)=\left(\frac{1}{l} \sum_{i=1}^{l}\left(\frac{\delta\left(b_{i}^{22}\right)-\delta\left(b_{i}^{22}\right)}{2 q}\right)^{2}\right)^{\frac{1}{2}}$

为标准的欧式距离。那么利用欧式距离公式计算的 方案 $x_{i}$ 与正、负理想解之间的加权距离 $D_{i}^{+}$和 $D_{i}^{-}$为:

$$
\begin{aligned}
& D_{i}^{+}=\sum_{j=1}^{m} w_{j} d\left(H_{s}^{i j}, H_{s}^{j+}\right) \\
& D_{i}^{-}=\sum_{j=1}^{m} w_{j} d\left(H_{S}^{i j}, H_{s}^{j-}\right)
\end{aligned}
$$

步骤 4 : 各方案 $x_{i}$ 与理想解的相对贴近度 $R C_{i}$

$$
R C_{i}=\frac{D_{i}^{-}}{D_{i}^{+}+D_{i}^{-}}, \quad \mathrm{i}=1,2, \ldots, \mathrm{n}
$$

其中相对贴近度越大代表着方案 $x_{i}$ 越优, 根据相对 贴近度的大小对方案 $x_{i}$ 进行排序。

\section{B. 基于犹豫模糊语言的 PROMETHEE 综合评价方法}

PROMETHEE 方法是一种级别高于关系的多属性决 策方法, 它最早是由 Brans 于 1984 年提出来的, 它要求 在决策中每一个备选方案的属性值都要与其他备选方案 的属性值进行两两比较, 使得每个备选方案都得到充分 的比较。PROMETHEE 方法中引入了优先函数来计算各 个方案在属性上的优先程度, 同时该方法不需要对指标 数据进行无量纲化处理和规范化处理, 从而避免了规范 化处理过程中出现的信息偏差的情况发生。 PROMETHEE 方法包含了 PROMETHEE I 方法和 PROMETHEE II 方法, 由于 PROMETHEE I 不能对各个 方案进行全排序, 故本文将采用 PROMETHEE II 方法进 行评价分析。

犹豫模糊语言作为决策者常用的表达形式, 在不确 定的环境下能够准确清晰的表达出决策者的偏好信息, 面对很多定性评估的问题, 犹豫模糊语言 PROMETHEE 方法可以有效的将定性问题转化为定量评估, 更加科学 准确的进行测量, 从而提供最佳方案。下面给出基于犹 豫模糊语言的 PROMETHEE 方法的计算步骤:

步骤 1 : 计算各个属性权重, 组成属性权重集合 $\mathrm{W}=\left\{W_{1}, W_{2}, \ldots W_{n}\right\}$, 其中 $0 \leqslant W_{j} \leqslant 1$, 且 $\sum_{j=1}^{n} W_{j}=1$, 本 文在这里介绍熵权法计算属性权重。熵权法确定属性权 重大致可以分为以下两步: 
（1）对 $\mathrm{m}$ 个方案 $\mathrm{n}$ 个属性的多属性决策矩阵 $\left(h_{i j}\right)_{n \times m}$, 计算第 $j$ 项指标的熵值:

$$
\begin{gathered}
e_{j}=-\frac{1}{\ln n} \sum_{i=1}^{n}(\varepsilon \ln \varepsilon), \sum_{i=1}^{n} h_{i j} \neq 0, j=1,2, \ldots \text { （6) } \\
\text { 其中, } \varepsilon=h_{i j}\left(\sum_{i=1}^{n} h_{i j}\right)^{-1}, \text { 当 } \varepsilon=0 \text { 时, } \ln \varepsilon=0 。
\end{gathered}
$$

（2）根据计算熵值的结果，计算各项属性的权重:

$$
w_{j}=1-e_{j} / \sum_{j=1}^{n}\left(1-e_{j}\right), j=1,2, \ldots,
$$

步骤 2: 确定优先函数。优先函数在 PROMETHEE 方法中是非常重要的, 利用优先函数可以计算在某一属 性上两个方案的优先程度, 文献[13]给出了 6 种经典的 优先函数, 分别为常用优先函数、 $\mathrm{U}$ 型优先函数、 $\mathrm{V}$ 型 优先函数、分级优先函数、无差异区间的 $\mathrm{V}$ 型优先函数

$$
\prod\left(A_{i}, A_{j}\right)=\sum_{k=1}^{n} W_{k} P_{k}\left(A_{i}, 1\right.
$$

步骤 3: 计算每个方案 $A_{i}$ 的流出量 $\Phi^{+}\left(A_{i}\right)$, 流入量 $\Phi^{-}\left(A_{i}\right)$, 和净流量 $\Phi\left(A_{i}\right)$ :

$$
\begin{gathered}
\Phi^{+}\left(A_{i}\right)=\sum_{A_{j} \in A} \prod\left(A_{i}, A_{j}\right. \\
\Phi^{-}\left(A_{i}\right)=\sum_{A_{j} \in A} \prod\left(A_{j}, A_{i}\right. \\
\Phi\left(A_{i}\right)=\Phi^{+}\left(A_{i}\right)-\Phi^{-}\left(A_{i}\right)
\end{gathered}
$$

\begin{tabular}{|c|c|c|c|c|}
\hline 区间 & \multicolumn{4}{|c|}{ 可接受区间 } \\
\hline 耦合协调数值 & $0.9<D \leqslant 1$ & $0.8<D \leqslant 0.9$ & $0.7<D \leqslant 0.8$ & $0.6<D \leqslant 0.7$ \\
\hline 耦合协调程度 & 优质协调发展 & 良好协调发展 & 中级协调发展 & 初级协调发展 \\
\hline 区间 & \multicolumn{4}{|c|}{ 过度区间 } \\
\hline 耦合协调数值 & \multicolumn{2}{|c|}{$0.5<\mathrm{D} \leqslant 0.6$} & \multicolumn{2}{|c|}{$0.4<D \leqslant 0.5$} \\
\hline 耦合协调程度 & \multicolumn{2}{|c|}{ 勉强协调发展 } & \multicolumn{2}{|c|}{ 濒临失调衰退 } \\
\hline 区间 & \multicolumn{4}{|c|}{ 不可接受区间 } \\
\hline 耦合协调数值 & $0.3<D \leqslant 0.4$ & $0.2<\mathrm{D} \leqslant 0.3$ & $0.1<D \leqslant 0.2$ & $0<D \leqslant 0.1$ \\
\hline 耦合协调程度 & 轻度失调衰退 & 中级失调衰退 & 重度失调衰退 & 极度失调衰退 \\
\hline
\end{tabular}

$\mathscr{D}^{+}\left(A_{i}\right)$ 是方案 $A_{i}$ 优于其他方案的总和, 它表示方案 $A_{i}$ 优于其他方案的程度; $\mathscr{D}^{-}\left(A_{i}\right)$ 是其他方案优于方案 $A_{i}$ 的总和, 它表示其他方案优于方案 $A_{i}$ 的程度; 根据各个 方案的净流量, 我们可以得到方案的全排序, $\Phi\left(A_{i}\right)$ 越

表 2 大数据产业与金融集聚耦合协调判定标准

和高斯型优先函数, 每种优先函数都有相对应的含义以 及适用条件，决策者可以根据面对的实际问题来进行选 择, 或者自行构造优先函数。但是无论选择哪种优先函 数, 都需要计算两个方案在某一属性下的差异程度, 即 $d_{j}\left(a_{i}, a_{k}\right)=\mathrm{f}\left(a_{i}\right)-\mathrm{f}\left(a_{k}\right)$, 然而在犹豫模糊语言环境下, 两个方案的表现描述形式为犹豫模糊语言, 无法进行直 接运算, 进而不能直接使用上述所说的 6 种优先函数, 所以在此本文借鉴文献[13]提出的改进的优先函数, 该 文献对 $\mathrm{V}$ 型优先函数进行了改进, 具体改进后的优先函 数表示为:

$$
P_{j}\left(a_{i}, a_{k}\right)=\left\{\begin{array}{cr}
0, & d_{j}\left(a_{i}, a_{k}\right) \leq 0 \\
\frac{d_{j}\left(a_{i}, a_{k}\right)}{\theta d_{j}\left(A_{j}^{+}, A_{j}^{-}\right)} & 0<d_{j}\left(a_{i}, a_{k}\right) \leq \theta d_{j}\left(A_{j}^{+},\right. \\
1, & d_{j}\left(a_{i}, a_{k}\right)>\theta d_{j}\left(A_{j}^{+}, A_{j}^{-}\right)
\end{array}\right.
$$

其中, $d_{j}\left(a_{i}, a_{k}\right)$ 表示在属性 $X_{j}$ 下，任意两个方 案 $a_{i}$ 和 $a_{k}$ 的 离 差, 即 $d_{j}\left(a_{i}, a_{k}\right)=\sigma_{s}^{i j}$ $\sigma_{s}^{k j}(i, k=1,2,3, \cdots, \mathrm{n}), \sigma_{s}^{i j}$ 为一个犹豫模糊语言集中所有 犹豫模糊语言数之和, 同理 $d_{j}\left(A_{j}^{+}, A_{j}^{-}\right)$表示正理想解与 负理想解的离差。另外 $0<\theta<1$, 决策者根据决策问题的 实际情况及其主观偏好可自主选择 $\theta$ 的取值。

步骤 4: 计算优先指数 $\Pi\left(A_{i}, A_{j}\right)$ 。优先指数表示方 案 $A_{i}$ 优于另一方案 $A_{j}$ 的程度, 优先指数越接近于 1 , 代 表方案的优度越好。
大表明方案的优度越高, $\Phi\left(A_{i}\right)$ 越小表明方案的优度越 低。

\section{C. 耦合协调模型}

本章采用源于物理学容量耦合系数模型的耦合协 调模型来测度大数据产业与金融集聚间的耦合协调程 度。耦合协调模型包含耦合度和耦合协调度, 用以反 映多个系统间相互作用和相互影响的程度。多个系统 相互作用的耦合度模型为:

$$
C_{n}=n\left[\left(U_{1} \cdot U_{2} \cdots U_{n}\right) / \Pi\left(U_{i}+U_{j}\right)\right]^{1 / n}
$$

式中 $\mathrm{n}$ 为耦合子系统个数, 则大数据产业一金融 集聚系统耦合度模型为:

$$
C_{2}=2 \sqrt{U_{1} \cdot U_{2}} /\left(U_{1}+U_{2}\right)
$$

式中 $C$ 为耦合度, 取值范围是 $[0,1]$, 当 $C=0$ 时, 表明两系统间互不影响; 当 $0<\mathrm{C} \leqslant 0.3$ 时, 系统处于 低水平耦合阶段; 当 $0.3<\mathrm{C} \leqslant 0.5$ 时, 系统处于拮抗 阶段; 当 $0.5<\mathrm{C} \leqslant 0$. 8 时, 系统处于磨合阶段; 当 0.8 $<\mathrm{C} \leqslant 1$ 时, 系统处于高水平耦合阶段。 $U_{1}$ 和 $U_{2}$ 分别为 大数据产业和金融集聚的综合评价值, 若两者实现耦 合协调发展, 当 $U_{1}-U_{2}>0.1$ 时, 为金融集聚滞后类 型; 当 $U_{2}-U_{1}>0.1$ 时, 为大数据产业滞后类型; 当 0 $\leqslant\left|U_{1}-U_{2}\right| \leqslant 0$. 1 时, 为大数据产业金融集聚同步类 型。若两者耦合处于失调衰退状态, 当 $U_{1}-U_{2}>0.1$ 
时，为金融集聚受损类型; 当 $U_{2}-U_{1}>0.1$ 时，为大 数据产业受损类型; 当 $0 \leqslant\left|U_{1}-U_{2}\right| \leqslant 0.1$ 时, 为大数 据产业金融集聚受损类型。

当两个系统的综合评价值相近且不高时，仅计算 耦合度会出现协同发展程度较高的伪评价结果。故为 准确反映大数据产业和金融集聚的耦合协调发展程 度，进一步构建耦合协调度模型：

$$
\begin{aligned}
& D=\sqrt{C \times T} \\
& T=\alpha U_{1}+\beta U_{2}
\end{aligned}
$$

式中 $\mathrm{D}$ 为耦合协调度, 取值范围为 $[0,1], T$ 为大数 据产业一金融集聚系统的综合评价值， $\alpha$ 和 $\beta$ 为待定系 数 $(\alpha+\beta=1)$, 反映大数据产业和金融集聚对整体系 统耦合协调作用的贡献程度，考虑二者对整体系统同 等重要, 选定 $\alpha=\beta=0.5$ 。整体系统耦合协调程度和对应 接受区间如表2所示。

\section{IV. 实证结果与分析}

将犹豫模糊语言 TOPSIS 法和犹豫模糊语言 PROMETHEE法得到的大数据产业和金融集聚的评价 值进行标准归一化, 运用得到贵州各地州市的大数据 产业发展水平和金融集聚水平标准化评价值来计算两 者的耦合度和耦合协调度，根据耦合协调度等级及划 分标准确定贵州各地州市大数据产业和金融集聚的耦 合协调程度如表3所示。

从表3可以看出, 贵阳市耦合协调度排名最高, 其 耦合协调度为 0.7071 , 大数据产业和金融集聚处于中 级协调发展状态; 遵义市的大数据产业和金融集聚处 于勉强协调发展状态, 其耦合协调度仅次于贵阳; 六 盘水市、毕节市和黔南州, 耦合协调度分别为 0.3242、0.3119和 0.3080 , 大数据产业和金融集聚处于 轻度失调衰退状态; 安顺、黔东南、铜仁和黔西南州 的大数据产业和金融集聚的耦合协调发展程度相近且 耦合协调度较低，处于中级失调衰退状态。

2013-2017年贵州各地州市的大数据产业与金融集聚 的耦合协调度处于平稳状态，但部分地区大数据产业 与金融集聚的处于不断协调发展的状态。其中，贵阳 市的在贵州省内间大数据产业和金融集聚的耦合协调 发展状况比较平稳且协调程度最高; 遵义市的大数据
产业和金融集聚的耦合协调发展程度不断提高，其耦 合协调度从 0.5179 上升到 0.6478 , 即从 2013 年勉强协调 上升到2017年的初级协调; 毕节市从2013年的中级失 调衰退上升为轻度失调衰退; 黔西南州的大数据产业 和金融集聚的耦合协调发展程度是最低的, 耦合协调 度由中级失调衰退上升为轻度失调衰退; 其余的地州 市, 大数据产业和金融集聚的耦合协调发展程度相差 不大，但在这五年内均有所发展。

\section{V. 结论与政策建议}

根据2013-2017年贵州九个地级市两个子系统的指 标原始数据, 运用耦合度模型、耦合协调度模型, 对 贵州地级市大数据产业-金融集聚耦合协调发展状况 进行实证分析, 得出以下结论:

（1）从总体上来看, 耦合协调程度普遍较低。 贵阳市和遵义市耦合协调类型属于中级协调发展和勉 强协调发展; 轻度失调衰退的有六盘水市、毕节市和 黔西南州; 其余四个属于中度失调衰退; 贵阳市和遵 义市属于大数据产业与金融集聚同步发展。

黔南州属于大数据产业发展滞后, 六盘水市、毕 节市、安顺市、黔西南州、黔东南州和铜仁市属于大 数据产业发展和金融集聚双滞后型。

（2）从空间上看, 中度协调发展和勉强协调发 展主要是经济比较发达的贵阳市和遵义市, 而轻度失 调发展和中级失调发展的主要是贵州的经济欠发达的 地区。所以, 说明贵州经济发达地区大数据产业-金 融集聚的协调发展程度明显高于经济欠发达地区。

(3) 从时间上来看, 耦合协调程度并非一成不 变。从2013年到2017年, 部分州市的耦合协调发展程 度有所上升。其中遵义市从2013年勉强协调上升到 2017年的初级协调; 毕节市从2013年的中级失调衰退 上升为轻度失调衰退; 黔南州也由中级失调衰退上升 为轻度失调衰退。

根据上述研究结论, 结合有关部门文件精神, 提 出以下政策建议:

(1) 对于大数据产业发展滞后型的地区, 围绕 拓展新兴信息服务业态, 推动大数据采集、加工、处 理、整合和深加工; 支持建立和引进大数据研发中

表 3 大数据产业与金融集聚耦合协调发展状况

\begin{tabular}{cccccccccc}
\hline 地区 & $\mathrm{D}_{2013}$ & $\mathrm{D}_{2014}$ & $\mathrm{D}_{2015}$ & $\mathrm{D}_{2016}$ & $\mathrm{D}_{2017}$ & $\mathrm{C}$ & $\mathrm{T}$ & $\mathrm{D}$ & 耦合协调类型 \\
\hline 贵阳市 & 0.7071 & 0.7071 & 0.7071 & 0.7071 & 0.7071 & 0.5000 & 1 & 0.7071 & 中级协调发展 \\
遵义市 & 0.5179 & 0.5470 & 0.5998 & 0.6463 & 0.6477 & 0.4904 & 0.7180 & 0.5917 & 勉强协调发展 \\
六盘水市 & 0.3214 & 0.3096 & 0.3475 & 0.3349 & 0.3079 & 0.4866 & 0.2165 & 0.3243 & 轻度失调衰退 \\
毕节市 & 0.2978 & 0.2706 & 0.2902 & 0.3334 & 0.3678 & 0.4978 & 0.1978 & 0.3119 & 轻度失调衰退 \\
黔南州 & 0.2860 & 0.3245 & 0.3009 & 0.3305 & 0.2981 & 0.4715 & 0.2022 & 0.3080 & 轻度失调衰退 \\
安顺市 & 0.2875 & 0.2991 & 0.3207 & 0.2813 & 0.2809 & 0.4786 & 0.1810 & 0.2939 & 中级失调衰退 \\
黔东南州 & 0.2997 & 0.2832 & 0.2791 & 0.2917 & 0.2895 & 0.4975 & 0.1675 & 0.2886 & 中级失调衰退 \\
铜仁市 & 0.2555 & 0.2751 & 0.2685 & 0.2758 & 0.2820 & 0.4986 & 0.1479 & 0.2714 & 中级失调衰退 \\
黔西南州 & 0.2236 & 0.2236 & 0.2236 & 0.2454 & 0.2442 & 0.4968 & 0.1087 & 0.2321 & 中级失调衰退 \\
\hline
\end{tabular}


心、工程技术 (研究) 中心等技术创新和产业化机构; 以大数据领域研发和产业化项目为载体, 积极引进高 端人才; 建设贵州省大数据平台, 整合贵州政务、公 共服务数据资源，建设数据资源灾备中心，不断完善 数据资源建设机制, 提升数据资源集聚和管理水平。

（2）对于大数据产业发展和金融集聚双滞后型 的地区，通过政策手段，引导各类风险投资机构加大 对大数据发展的投资力度，鼓励金融机构为符合条件 的大数据企业提供贷款，拓宽大数据企业融资渠道; 引导和鼓励金融机构支持贵州科技金融体系建设和投 资，鼓励金融机构为符合条件的大数据企业给予信贷 支持，围绕大数据产业开发和创新金融产品，延伸服 务网络，为贵州大数据项目融资提供支撑。

致谢

本项目受国家自然科学基金地区项目（71861003）; 2017 年度第二批贵州省基础研究计划（软科学类别）项 目（黔科合基础（2017）1516-1）资助。

\section{参考文献}

[1] Raja, Raghuran G, luigr Zingales. Financial Dependence and Growth[J]. American Economic Reviews, 1998,88(3):559-586.

[2] Audress D, Feldman M.006. Spillovers and the geography of innovation and production $[\mathrm{J}]$. American Economic Review,86( 3):630-640.

[3] Cotugno M, Monferra S, Sampagnaro G. 2013. Relationship lending, hierarchy distance and credit tightening: evidence from the financial crisis[J]. Journal of Banking \& Finance, 37( 5):1372-1385.

[4] Carlin, Mayer. Financial, investment and growth[J]. Journal of Financial Economics, 2003, 69(01):1991-226.

[5] 陈峰. 论产业结构调整中金融的作用[J]. 金融研究, 1996(11).

[6] 孙晶, 蒋伏心. 金融集聚对区域产业结构升级的空间溢出效应研究 一一基于 2003-2007 年省际经济数据的空间计量分析[J]. 产经评 论, 2013(1).

[7] 杨义武,方大春.金融集聚与产业结构变迁一一来自长三角 16 个城 市的经验研究 [J].金融经济学研究,2013,28(06):55-65.

[8] 邓向荣,刘文强.金融集聚对产业结构升级作用的实证分析[J].南京 社会科学, 2013(10):5-12+20.

[9] 何宜庆,王耀宇,周依仿,周紫薇.金融集聚、区域产业结构与生态效 率耦合协调实证研究——以三大经济圈为例 $[\mathrm{J}]$. 经济问题探 索,2015(05):131-137.

[10] 郭露,丁峰.产业结构、金融集聚与协调发展:长三角地区 16 个地 市 1994 2013 的实证研究[J].经济体制改革,2015(05):59-65.

[11] 于斌斌.金融集聚促进了产业结构升级吗:空间溢出的视角一一基 于中国城市动态空间面板模型的分析 [J]. 国际金融研 究,2017(02):12-23.

[12] 谢婷婷,潘宇.丝绸之路经济带产业结构与金融集聚耦合评价及空 间分异研究[J].武汉金融,2017(11):18-25。

[13] 郭涁,张笑.金融集聚与产业结构升级耦合协调性研究 [J].管理现代 化,2018,38(05):31-34.

[14] 张目,周宗放.基于粗集和熵权-TOPSIS 法的高新技术企业自主创 新能力评价 $[\mathrm{J}]$.数学的实践与认识,2008,38(24):52-58.

[15] 廖虎昌,杨竹,徐泽水,顾新.犹豫模糊语言 PROMETHEE 方法在川 酒品牌评价中应用 [J/OL].控制与决策:1-10[2019-04-13].

[16] 魏翠萍,葛淑娜. 犹豫模糊语言幂均算子及其在群决策中的应用 $[\mathrm{J}]$. 系统科学与数学, 2016,36(08):1308-1317.

[17] 白彩全,黄芽保,宋伟轩等.省域金融集聚与生态效率耦合协调发展 研究[J].干旱区资源与环境, 2014,28(9):1-7 